\title{
Changing Trends on the Place of Delivery among Rural Women's of Allahabad District in Uttar Pradesh, India
}

\author{
Amit Kumar Singh ${ }^{1}$ \\ $\&$ \\ Prof. V.K.Kumra ${ }^{2}$ \\ Senior Research Fellow ${ }^{1} \&$ Professor ${ }^{2}$, Department of Geography, Banaras Hindu University, Varanasi, \\ Department of Geography, BHU.
}

\begin{abstract}
Delivery care is crucial for both maternal and prenatal health. Increasing skilled attendance at birth is a central goal of safe motherhood and child survival. The main aim of this study is to identify whether place of delivery is changing over time. And also to assess the socio-economic and demographic factors influencing women's decision for choice of place of delivery in rural areas of Allahabad district of Uttar Pradesh. This study is conducted in 20 selected villages by using purposive random sampling. For this purpose 800 women belonging to age group of 15-49 years were surveyed during July 2015-June 2016. The result of the study shows that 51.3 per cent of deliveries have been taken place at health care institutions and only 48.7 per cent of deliveries took place at home. All women who had completed higher secondary education were preferred health care institutions for their delivery (during last birth). The key factors influencing choice of place of delivery is education, age at marriage, low standard living condition. Having a distant health center, lack of transportation and financial constraints are the other main reasons for choosing a home delivery. It concludes that trend of delivery at health institution is remarkably increased but there is found strong differentials in low socio-economic status of women.
\end{abstract}

Key words: Place of Delivery, Antenatal, Prenatal and Postnatal.

\section{INTRODUCTION}

The Women is the pivot around which the family, society and humanity itself revolves. It is well said that the hands that rock the cradle, rule the world. Women play a significant role in the development of their offspring. Truly if a man is educated, one person is educated but if the woman is educated, the whole family is educated. Indeed it encompasses preconception, prenatal and postnatal care. Preconception care implies health promotion, screening and interventions of women for reproductive age for reducing risk factors during future pregnancy. Prenatal care includes comprehensive care which women receive throughout their pregnancy. It is said that women having prenatal care early in their pregnancies give better birth outcome than their counterpart who do not receive due care during their pregnancies. Post natal care addresses recovery from child birth, care of new born, nutrition, breastfeeding and family planning. The major direct causes of maternal morbidity and mortality include, hemorrhage, infection, high blood pressure, unsafe abortion and obstructed labour.

Maternal health refers to the health of women during pregnancy and at the time of birth of child. It consists of overall health care of the women pertaining to reproductive health, health status, mortality and morbidity. Reproductive health is a vital aspect of the maternal health. It encompasses a broad range of issues related to antenatal care, health complications during pregnancy and post natal care. Antenatal care refers to pregnancy related health care, which is provided by a doctor, an ANM or by other health care professionals. The primary aim of antenatal care is to produce a safe and healthy outcome with regards to both mother and child at the end of the pregnancy. India's maternal mortality ratio is high compared to many other Asian countries. The latest figure states that there are about 174 maternal deaths per 100,000 live births (WHO, 2015). However, this average hides a wide range: from 66 in Kerala to 292 in Uttar Pradesh/Uttrakhand. This is much higher than neighbouring countries such as China (27), Thailand (20), Malaysia (40) and Sri Lanka (30) (UNFPA, 2015). Pregnant women die in India due to certain important factors, ranging from poverty, to ineffective or unaffordable health services (Mayhew, et. al. 1998).In India, while 50 per cent of pregnant women receive some form of antenatal check up (WHO, 2013), only 41 per cent deliver in an institution (IIPS, 2007). Again this is an average, which does not reveal that only 13 per cent of the lowest income quintile delivers in a hospital, even though all services are free for them. While many women felt that institutional delivery is not necessary, a quarter interviewed expressed that they could not afford to deliver in a health care centres (IIPS, 2007). Recent analysis of the third National Family Health Survey (2005-06) shows 13 per cent of women in the lowest wealth quintile accessing institutional delivery care compared with 84 per cent in the highest (Vora, et. al. 2009). India's Child Survival and Safe Motherhood Programme (CSSM), launched in 1992, involved training 
of physicians and Trained Birth Attendants (TBAs), provision of aseptic delivery kits and expansion of existing rural health services to include facilities for institutional delivery i.e. supply of essential equipment to district, sub-district and first level referral facilities to deal with high risk obstetric emergencies (MoHFW, 1997-08). The initiative aimed to improve the proportion of pregnant women receiving three antenatal visits, and the proportion of deliveries conducted by trained attendants. The CSSM gave way to Reproductive and Child Health (RCH) programme in 1997, at which point the scope was widened to include other reproductive and child health services (Dadhich, et al. 2004). The institutional deliveries in the country have increased from 38.7 per cent as per the National Family Health Survey (NFHS-III) in 2005-06 to 46.9 per cent as per District Level Household Survey (DLHS-III) in 2007-08. As per the Coverage Evaluation Survey (CES, 2009) conducted by the UNICEF, the institutional delivery is 72.9 per cent. In India institutional delivery rate in rural and urban areas were found 37.8 per cent and 70.4 per cent respectively (DLHS-III) in the year 2007-08. Highest 99.2 per cent institutional deliveries found in rural areas of Kerala while it is found lowest (13.3\%) in Chhattisgarh state. In rural areas of the Uttar Pradesh it is found only 22 per cent. Keeping this in view, the present study is being conducted to know the utilisation of delivery care services in rural areas of Allahabad district. It shows the relationship between socio-economic characteristics of the respondents and their utilisation pattern of delivery care services. An attempt is also made to identify the factors, which affect utilisation pattern. To assess the utilisation pattern of delivery care services in rural areas of the district 800 persons were interviewed covering all the development blocks and different cross-sections of the community and results thus obtained were tabulated.

\section{STUDY AREA}

The district of Allahabad $\left(24^{\circ} 47^{\prime} \mathrm{N}\right.$ and $25^{\circ} 47^{\prime} \mathrm{N}$ latitudes and between $81^{\circ} 19^{\prime} \mathrm{E}$ and $82^{\circ} 30^{\prime} \mathrm{E}$ longitudes) covers an area of $5,246 \mathrm{~km}^{2}$. It is located in the southern part of Uttar Pradesh. The northern part of the district lies in the Gangetic Plain whereas southern part comes under Vindhyan Plateau. To its south and south-east is the Bagelkhand region, to its north and north-east is the Awadh region, and to its west along with Kaushambi it forms the part of Doab i.e. the lower Doab region. Allahabad district is surrounded by the districts of Bhadohi and Mirzapur in the east, Kaushambi and Banda in the west, Pratapgarh and Jaunpur in the north and Banda and Madhya Pradesh in the south. The River Ganga and Yamuna flow through the district. The mainstay of economy is primarily agriculture. The region is characterized by developmental constraints in terms of rapidly growing population, lack of appropriate transportation, adequate health care delivery and education.

\section{STUDY OBJECTIVES}

In the light of above facts, an attempt has been made to discuss some aspects for institutional delivery at full length in this paper. This work is fully based on the primary data generated through a well designed questionnaire. The major objectives of this study area are

(i) To identify the relationship between institutional delivery and socio economic determinants and

(ii) To run the logistic regression for predicting association between institutional delivery and socio economic determinants.

\section{MATERIALS AND METHODS}

Relevant literatures have been consulted from the different sources to collect literatures, reports, publications and articles based on the topic. The present study based on primary data for the year 2015-16 obtained from questionnaire based survey of 800 respondents selected from 20 villages. To give the due representation to each prominent community as per their share in the total population, sample includes 44.75 per cent General category, 36.5 per cent Other Backward category (OBC), 18.75 per cent and Scheduled Caste/ Scheduled Tribes (SC/ST) category. After completing the questionnaires, the process of tabulation of data has been start by using SPSS (16.0) programme exclusively. Results were summarized and presented as frequencies and percentages and also Chi-square test is used for assessing the statistical significance at p-value. Logistic regression has also been run to know the association between various socio- economic determinants and utilization of maternal health care.

\section{RESULTS AND DISCUSSIONS}

Institutional delivery means giving birth to a child at a medical institution under the overall supervision of trained and competent health personnel where there are more amenities available to handle the situation and save the life of the mother and child. If the child is born at home, then chances of getting infected from unhygienic environment are more and it is very tough and sometimes impossible to handle child-birth complications. Institutional births result in reduced infant and maternal mortality and increased overall health status of the mother and the child. 
Place of delivery: All the women who participated in this research study were asked their place of delivery during last child birth and the result are tabulated. Figure 1 reveals that significant proportion of the deliveries was taken place in health institution (51.3\%); of this 34.6 per cent performed at government hospitals and 16.7 per cent conducted at private hospitals, whereas, 48.7 per cent of the total deliveries were conducted at home with the help of trained health workers or relatives.

\section{Place of Delivery}

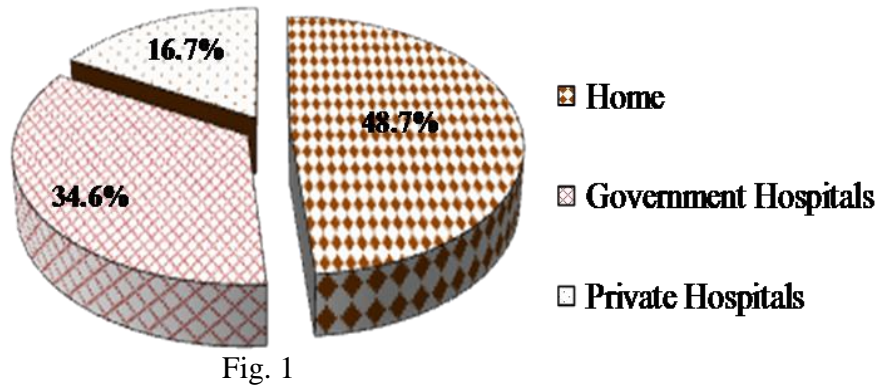

Assistance while delivery: Figure 2 discloses that out of the total 800 respondents, 24.4 per cent of home deliveries were assisted by friends or relatives and the remaining deliveries were attended by health professionals $(75.6 \%)$. It can be clear that though a significant proportion of child deliveries happened at homes, half of the child deliveries were attended by trained health workers. With regard to institutional deliveries, more than thirty per cent of deliveries were conducted by doctors and the remaining 44.7 per cent of deliveries were conducted by Auxiliary Nurse Midwives (ANM) and Trained Birth Attendants (TBA or Dai).

\section{Assistant during Delivery}

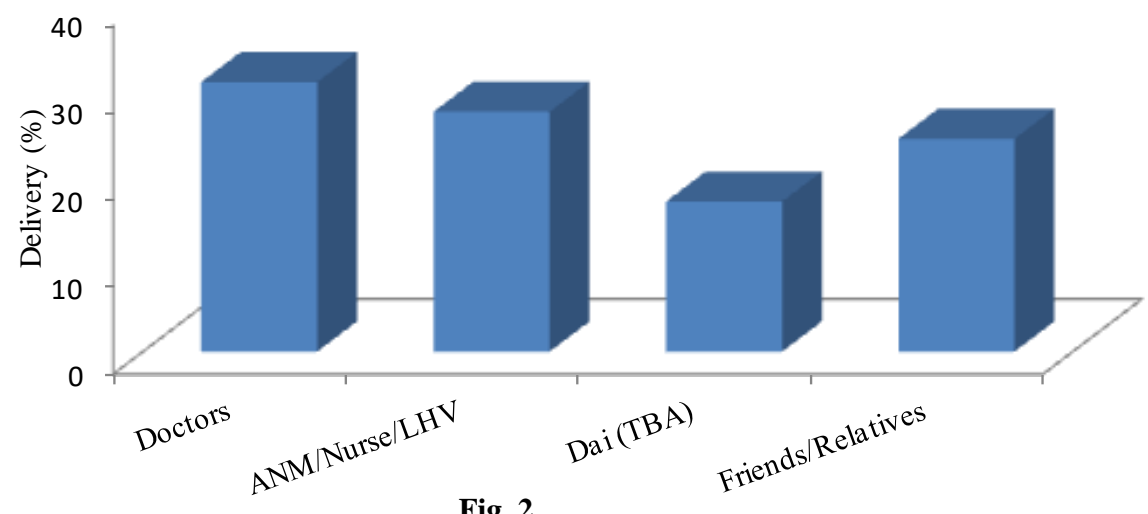

Fig. 2

Table 1.1 reflects the details of religion, social group and the level of income of the couples and their preference (home or institutional delivery) for child birth. Out of the total 800 respondents, there are 690 Hindu and 110 Muslim families. It is clear from the Table 3.19 that out of total Hindu respondents, 216 families (31.3\%) preferred to go for delivery by doctor where as 198 families contracted ANM/nurse/LHV, friends/relatives assisted 155 (22.5\%) families and Dai (TBA) assisted 121 (17.5\%) families for delivery of child. It is further observed that among Muslim respondents maximum number (36.4\%) of families got assistance for child birth from friends/relatives followed by 28.2 per cent (31 families) taken help of doctor, 20 per cent (22 families) were assisted by ANM/nurse/LHV and 15.5 per cent (17 families) through Dai (TBA).

Table 1.1 also reveals pattern of delivery type among different social groups. Out of the total respondents, maximum (358 families) belongs to general category followed by OBC (292 families) and SC/ST (150 families). In general category majority of respondents (119 families) believe in doctor for their child birth while 107 families (29.9\%) go for ANM/nurse/LHV for delivery. In rest of the families friends/relatives assisted 20.7 per cent (74 families) and Dai (TBA) assisted 16.2 per cent (58 families) for delivery of child. Maximum percentage of respondents $(29.5 \%)$ preferred doctors for child delivery, whereas, 27.4 per cent (80 families) by friends/relatives, 26 per cent (76 families) by ANM/nurse/LHV and 17.1 per cent (50 families) with the help of Dai (TBA). Similar trend was also found in the case of SC/STs for birth of their child.

Table 1.1: Assistance of Delivery at the Time of Last Birth

\begin{tabular}{|c|c|c|c|c|c|c|c|c|}
\hline \multirow[t]{3}{*}{ Attributes } & \multicolumn{7}{|c|}{ Who assisted delivery of child in your family (last birth)? } & \multirow[t]{2}{*}{ Total } \\
\hline & Doctor & & urse/LHV & Dai & $\overline{\mathrm{BA})}$ & Frie & /Relatives & \\
\hline & \begin{tabular}{l|l} 
No. & $\%$ \\
\end{tabular} & No & $\%$ & No. & $\%$ & No. & $\%$ & No \\
\hline
\end{tabular}


Changing Trends on the Place of Delivery among Rural Women's

\begin{tabular}{|c|c|c|c|c|c|c|c|c|c|c|}
\hline \multicolumn{11}{|l|}{ Religion } \\
\hline Hindu & 216 & 31.3 & 198 & 28.7 & 121 & 17.5 & 155 & 22.5 & 690 & 100 \\
\hline Muslim & 31 & 28.2 & 22 & 20.0 & 17 & 15.5 & 40 & 36.4 & 110 & 100 \\
\hline Total & 247 & 30.9 & 220 & 27.5 & 138 & 17.2 & 195 & 24.4 & 800 & 100 \\
\hline \multicolumn{11}{|c|}{$\chi^{2}=10.667^{\mathrm{a}}, \quad \mathrm{df}=3, \quad \mathrm{P}=0.014$} \\
\hline \multicolumn{11}{|c|}{ Social Category } \\
\hline SC/ST & 42 & 28.0 & 37 & 24.7 & 30 & 20.0 & 41 & 27.3 & 150 & 100 \\
\hline $\mathrm{OBC}$ & 86 & 29.5 & 76 & 26.0 & 50 & 17.1 & 80 & 27.4 & 292 & 100 \\
\hline General & 119 & 33.2 & 107 & 29.9 & 58 & 16.2 & 74 & 20.7 & 358 & 100 \\
\hline Total & 247 & 30.9 & 220 & 27.5 & 138 & 17.2 & 195 & 24.4 & 800 & 100 \\
\hline \multicolumn{11}{|c|}{$\chi^{2}=7.190^{\mathrm{a}}, \quad \mathrm{df}=6, \quad \mathrm{P}=0.304$} \\
\hline \multicolumn{11}{|c|}{ Level of Income } \\
\hline Upto 5000 & 71 & 30.3 & 71 & 30.3 & 34 & 14.5 & 58 & 24.8 & 234 & 100 \\
\hline $5000-10000$ & 81 & 32.9 & 70 & 28.5 & 33 & 13.4 & 62 & 25.2 & 246 & 100 \\
\hline $\begin{array}{l}10000- \\
15000\end{array}$ & 70 & 29.2 & 53 & 22.1 & 55 & 22.9 & 62 & 25.8 & 240 & 100 \\
\hline $\begin{array}{l}15000- \\
20000\end{array}$ & 6 & 15.8 & 16 & 42.1 & 11 & 28.9 & 5 & 13.2 & 38 & 100 \\
\hline$>20000$ & 19 & 45.2 & 10 & 23.8 & 5 & 11.9 & 8 & 19.0 & 42 & 100 \\
\hline Total & 247 & 30.9 & 220 & 27.5 & 138 & 17.2 & 195 & 24.4 & 800 & 100 \\
\hline \multicolumn{11}{|c|}{$1^{\mathrm{a}}, \quad \mathrm{df}=12, \quad \mathrm{P}=0.009$} \\
\hline
\end{tabular}

Source: Based on personal survey, 2015-16.

The data also shows income status of the families and their preference for institutional and noninstitutional deliveries. Among all the income groups, maximum respondents have preferred to go for doctor and ANM/nurse/LHV for safe delivery of child. Majority of families belong to income group of Rs. 15,00020,000 who believe in ANM/nurse/LHV instead of others for child birth.

Reasons for not getting delivery facilities

Women who did not delivered child at healthcare centres $(n=321)$ were asked to state reasons for not delivering child at health centres. Table 1.2 presents the percentage distribution of women according to main reasons for not going to health institution for safe delivery. In the study area, around 27.1 per cent of the women who have delivered child at home reported that they have better care at home itself. Another 43 per cent women reported that there is no need to go for child delivery to the health centers. It is perhaps due to social myth and faith in their trained Dai. It is also observed that 52.3 per cent of women stated that due to non-availability of transportation facility they could not reach the health centre. A quite significant proportion of women reported that due to poor quality of services they did not prefer to visit the health centers for child delivery (57\%). About 24.6 per cent women have not visited health centre because of higher cost. About 15 per cent of women stated that they had no time to visit the health institution for safe delivery.

Table 1.2: Percentage of women by Reasons for not going to health institution for child delivery

\begin{tabular}{|l|r|r|r|l|}
\hline \multirow{2}{*}{ Causes behind not going for Safe Delivery } & \multicolumn{1}{|c|}{ Responses } & \multicolumn{1}{l|}{ Total } \\
\cline { 2 - 5 } & \multicolumn{1}{|c|}{ No. } & \multicolumn{1}{c|}{ No. } & \multicolumn{1}{c|}{$\%$} \\
\hline Not Necessary & 138 & 43.0 & 321 & 100 \\
\hline Too Much Cost & 79 & 24.6 & 321 & 100 \\
\hline Too Far/ No Transport Facility & 168 & 52.3 & 321 & 100 \\
\hline Poor Quality Services & 183 & 57.0 & 321 & 100 \\
\hline No Time to Go & 48 & 15.0 & 321 & 100 \\
\hline Better Care at Home & 87 & 27.1 & 321 & 100 \\
\hline Lack of Knowledge & 32 & 10.0 & 321 & 100 \\
\hline
\end{tabular}

Source: Based on personal survey, 2015-16.

Place of delivery by socio-economic and demographic conditions

It is essential that delivery should be conducted under proper hygienic conditions with the help of a trained medical practitioner. The provision of child delivery care at the public health institutions is one of the components of the RCH (Reproductive and Child Health) programme. Despite several efforts made by the governmental and non-governmental institutions, more than one-third of child birth takes place at home. The Table 1.3 shows the percentage distribution of women's place of delivery by their socio-economic and demographic conditions.

Table 1.3: Place of delivery according to respondents background characteristics

\begin{tabular}{|c|c|c|c|c|c|c|c|c|}
\hline \multirow[t]{3}{*}{ Attributes } & \multicolumn{6}{|c|}{ Place of Delivery } & \multirow{2}{*}{\multicolumn{2}{|c|}{ Total }} \\
\hline & \multicolumn{2}{|c|}{ Home } & \multicolumn{2}{|c|}{ Govt. Institution } & \multicolumn{2}{|c|}{ Pvt. Hospital } & & \\
\hline & No. & $\%$ & No. & $\%$ & No. & $\%$ & No. & $\%$ \\
\hline \multicolumn{9}{|l|}{ Age-group } \\
\hline $15-24$ & 155 & 41.7 & 155 & 41.7 & 62 & 16.7 & 372 & 100 \\
\hline
\end{tabular}


Changing Trends on the Place of Delivery among Rural Women's

\begin{tabular}{|c|c|c|c|c|c|c|c|c|}
\hline $25-34$ & 76 & 33.0 & 121 & 52.6 & 33 & 14.3 & 230 & 100 \\
\hline $35-44$ & 52 & 43.3 & 44 & 36.7 & 24 & 20.0 & 120 & 100 \\
\hline 45 and Above & 38 & 48.7 & 27 & 34.6 & 13 & 16.7 & 78 & 100 \\
\hline \multicolumn{9}{|c|}{$\chi^{2}=13.778^{\mathrm{a}}, \mathrm{df}=6, \quad \mathrm{P}=0.032$} \\
\hline \multicolumn{9}{|c|}{ Level of Education } \\
\hline Illiterate & 61 & 43.6 & 57 & 40.7 & 22 & 15.7 & 140 & 100 \\
\hline Primary & 118 & 46.5 & 97 & 38.2 & 39 & 15.4 & 254 & 100 \\
\hline High school & 57 & 38.5 & 76 & 51.4 & 15 & 10.1 & 148 & 100 \\
\hline Intermediate & 48 & 35.3 & 66 & 48.5 & 22 & 16.2 & 136 & 100 \\
\hline $\begin{array}{l}\text { Graduation } \\
\text { and Above }\end{array}$ & 37 & 30.3 & 51 & 41.8 & 34 & 27.9 & 122 & 100 \\
\hline \multicolumn{9}{|c|}{$\chi^{2}=25.088^{\mathrm{a}}, \mathrm{df}=8, \quad \mathrm{P}=0.002$} \\
\hline \multicolumn{9}{|c|}{ Social Category } \\
\hline SC/ST & 71 & 47.3 & 63 & 42.0 & 16 & 10.7 & 150 & 100 \\
\hline $\mathrm{OBC}$ & 124 & 42.5 & 122 & 41.8 & 46 & 15.8 & 292 & 100 \\
\hline General & 126 & 35.2 & 162 & 45.3 & 70 & 19.6 & 358 & 100 \\
\hline \multicolumn{9}{|c|}{$\chi^{2}=10.251^{\mathrm{a}}, \mathrm{df}=4, \quad \mathrm{P}=0.036$} \\
\hline \multicolumn{9}{|c|}{ Level of Income } \\
\hline Upto 5000 & 99 & 42.3 & 111 & 47.4 & 24 & 10.3 & 234 & 100 \\
\hline $5000-10000$ & 93 & 37.8 & 106 & 43.1 & 47 & 19.1 & 246 & 100 \\
\hline $10000-15000$ & 108 & 45.0 & 96 & 40.0 & 36 & 15.0 & 240 & 100 \\
\hline $15000-20000$ & 11 & 28.9 & 19 & 50.0 & 8 & 21.1 & 38 & 100 \\
\hline$>20000$ & 10 & 23.8 & 15 & 35.7 & 17 & 40.5 & 42 & 100 \\
\hline \multicolumn{9}{|c|}{$\chi^{2}=30.454^{\mathrm{a}}, \mathrm{df}=8, \quad \mathrm{P}=0.001$} \\
\hline \multicolumn{9}{|l|}{ Occupation } \\
\hline $\begin{array}{l}\text { Agricultural } \\
\text { Labourer }\end{array}$ & 118 & 37.3 & 145 & 45.9 & 53 & 16.8 & 316 & 100 \\
\hline Service & 61 & 35.9 & 86 & 50.6 & 23 & 13.5 & 170 & 100 \\
\hline $\begin{array}{l}\text { Commercial } \\
\text { Trader }\end{array}$ & 20 & 43.5 & 16 & 34.8 & 10 & 21.7 & 46 & 100 \\
\hline Cultivator & 4 & 28.6 & 8 & 57.1 & 2 & 14.3 & 14 & 100 \\
\hline $\begin{array}{l}\text { Daily Wage } \\
\text { Earner }\end{array}$ & 68 & 56.7 & 36 & 30.0 & 16 & 13.3 & 120 & 100 \\
\hline Others & 50 & 37.3 & 56 & 41.8 & 28 & 20.9 & 134 & 100 \\
\hline Total & 321 & 40.1 & 347 & 43.4 & 132 & 16.5 & 800 & 100 \\
\hline
\end{tabular}

Source: Based on personal survey, 2015-16.

Table 1.3 shows bivariate analysis of place of delivery by each of the explanatory variables. The results reveal that out of the total delivery cases (800), 40.1 per cent have taken place at home, 43.4 per cent delivery cases were performed at government hospitals, and 16.5 per cent deliveries conducted at private hospitals and clinics. Table shows that middle age-group females (25-34 years) have more access to safe delivery (Government and Private institution) as compared to older age-group. Utilisation of institutional and home delivery is found to be significantly associated with the age-group of female family member $\left(\chi^{2}=13.778^{\mathrm{a}}, \mathrm{P}<\right.$ 0.05).It is assumed that educational status of family plays a significant role in making decision with regard to place of delivery. Education wise place of delivery is given in Table 1.3 which portrays substantial variation. For instance, the proportion of home delivery is highest (46.5\%) among those are educated upto primary level followed by illiterate $(43.6 \%)$ and educated upto high school (38.5\%). Contrary to this, the highest proportion of institutional deliveries $(69.67 \%)$ are found among highly educated respondents e.g. graduation and above. Thus, it can be inferred that with increasing level of education the proportion of institutional or safe deliveries in hygienic condition is also increasing in the study area. The hypothesis that 'there is no association between level of education of family and the institutional delivery is rejected by the Chi-square test of significance. This implied that there is a significant association between educational status of family and safe delivery $\left(\chi^{2}=\right.$ $\left.25.088^{\mathrm{a}}, \mathrm{P}=0.002\right)$. Akin to education, income of the family also plays an important role in making decision for safe delivery. Table 1.3 depicts income wise place of deliveries. It exhibits significant variation. But variations therein are in positive direction. For instance, number of institutional delivery is increasing among the respondents having higher income. About 76.2 per cent institutional deliveries have been reported from respondents belonging to high income group $(>20,000)$. The economic polarization within the society and lack of social security system make the poor people more vulnerable in terms of affordability and choice of health provider (Asenso, et. al., 1998). Chi-square test reveals that, there is found significant difference among different income groups and adoption of safe delivery as the information is obtained $\left(\chi^{2}=30.454^{\mathrm{a}}, \mathrm{P}=0.001\right)$.

Table 1.3 also reveals place of deliveries according to occupational structure. Remarkable variation is found in deliveries performed at home and healthcare institutions among the respondents deriving their livelihood through various occupations. Most striking feature of this analysis is that out of the total 321 deliveries performed at home, the highest proportion of home delivery $(56.7 \%)$ were performed among families of daily 
wage earners followed by 43.5 per cent respondents engaged in commercial trade, while lowest number of home delivery was performed among cultivator $(28.6 \%)$ and service category (35.9\%). However, highest deliveries performed at institution are found among respondents engaged in cultivation (71.4\%), followed by services $(64.1 \%)$ whereas minimum reported among daily wage earner category. The variation found among occupational categories regarding home and safe or institutional deliveries are statistically significant $\left(\chi^{2}=\right.$ $23.363^{\mathrm{a}}, \mathrm{P}=0.009$ ). The perusal of institutional delivery in terms of sex (male or female) reveals no obvious variation $(\mathrm{P}>0.837)$. Table 1.3 reveals home and institutional deliveries according to social categories of the respondents. The deliveries performed in unhygienic condition at home are found highest in SC/ST category $(47.3 \%)$ while it is lowest in general category $(35.2 \%)$ of the total deliveries conducted. Contrary to this highest (64.9\%) safe or institutional deliveries is performed in family members of general category followed by OBC (57.6\%) and lowest (52.7\%) among SC/ST categories. This analysis shows that there is significant association between social categories and safe deliveries $\left(\chi^{2}=10.251^{\mathrm{a}}, \mathrm{P}=0.036\right)$.

\section{MULTIVARIATE ANALYSIS}

To assess the effect of various attributes on adopting safe or institutional delivery Multivariate Analysis has been done. For this a number of variable (Table 1.4) were taken. This table shows the result of multivariate analysis assessing the association between utilisation of healthcare facilities for safe delivery and the explanatory variables. On account of the smaller sample size the categories of some variables are merged into two or three categories. For the analysis 95 per cent confidence interval are also presented in the given Table. The binary logistic result shows that respondent's religion, social category, age-group, and level of education were significantly associated with place of delivery in hygienic conditions. The probability for opting institutional delivery is slightly higher among Muslims (Odds ratio 1.786) than the Hindus.

Table 1.4: Logistic Regression Results Predicting the Odds of having Safe Delivery (Institutional Delivery) according to Selected Socio-economic and Demographic Characteristics

\begin{tabular}{|c|c|c|c|c|c|}
\hline \multirow[t]{2}{*}{ Attributes } & \multirow[t]{2}{*}{$\begin{array}{l}\text { Covariates and } \\
\text { Categories }\end{array}$} & \multirow[t]{2}{*}{ Significance } & \multirow[t]{2}{*}{$\begin{array}{c}\text { Odds Ratio } \\
\text { Expected ( } \beta)\end{array}$} & \multicolumn{2}{|c|}{$\begin{array}{l}95 \% \text { C.I. for } \\
\text { EXP(B) }\end{array}$} \\
\hline & & & & Lower & Upper \\
\hline \multirow[t]{3}{*}{ Age Group } & $<30^{\circledR}$ & .007 & & & \\
\hline & $31-45$ & .003 & $.567 * *$ & .390 & .824 \\
\hline & $>45$ & .728 & .934 & .635 & 1.373 \\
\hline \multirow[t]{2}{*}{ Sex } & Male $^{\circledR}$ & & & & \\
\hline & Female & .404 & .880 & .652 & 1.188 \\
\hline \multirow[t]{3}{*}{ Social Category } & $\mathrm{SC} / \mathrm{ST}^{\circledR}$ & .023 & & & \\
\hline & OBC & .214 & .759 & .491 & 1.172 \\
\hline & General & .008 & $.580 * *$ & .388 & .866 \\
\hline \multirow[t]{2}{*}{ Family Type } & Joint $^{\circledR}$ & & & & \\
\hline & Nuclear & .297 & 1.168 & .872 & 1.564 \\
\hline \multirow[t]{4}{*}{ Education } & Literacy & & & & \\
\hline & Illiterate $^{\circledR}$ & .052 & & & \\
\hline & Upto Intermediate & .639 & .906 & .598 & 1.371 \\
\hline & Graduation \& Above & .030 & $.509 *$ & .277 & .935 \\
\hline \multirow[t]{3}{*}{ Income } & $<5000^{\circledR}$ & .234 & & & \\
\hline & 5001- 10000 & .576 & 1.105 & .780 & 1.565 \\
\hline & $>10000$ & .230 & .683 & .367 & 1.272 \\
\hline \multirow[t]{3}{*}{ Occupation } & Labourer $^{\circledR}$ & .154 & & & \\
\hline & Services & .261 & .791 & .526 & 1.190 \\
\hline & Others & .069 & .698 & .473 & 1.029 \\
\hline \multirow[t]{3}{*}{ Religion } & Hindu $^{\circledR}$ & & & & \\
\hline & Muslim & .011 & $1.786^{*}$ & 1.141 & 2.797 \\
\hline & Constant & .310 & 1.334 & & \\
\hline
\end{tabular}

Source: Based on personal survey, 2015-16.

Similarly in comparison to SC/ST the probability for choosing safe delivery is significantly higher in case of General category $(\mathrm{P}<0.05$, Odds ratio 0.509$)$. Age-group of the respondents is also positively associated with safe delivery. Analysis revealed that education has a strong association with place of safe delivery for instance, odds ratio for respondents education upto intermediate and above intermediate level (graduation and above) are 0.906 and $0.509(\mathrm{P}<0.05)$ times more respectively than that of illiterate ones. In this analysis category of SC/ST, illiterate, and age-group belongs to less than 30 years has been referenced one that is why the odds ratio is less for other categories among caste, education and age. This proves the hypothesis that utilisation of healthcare facilities is directly proportional to the socio-economic conditions of respondents. 
Considerable variations in the place of safe delivery were found across the religion, social category, occupation, education, income group, and age-group. Beside this religion, social category, age-group, and level of education have been found major predictor for encouraging institutional delivery in hygienic conditions. There is need of concerted effort by the governmental and non-governmental organizations to motivate people belonging to different religion and social categories for opting institutional delivery.

\section{CONCLUSION}

This study investigates individual, socio-economic, demographic and health services related factors that are associated with the place of delivery. Women's educational level, their standard of living, and health care facilities were most predictive of place of delivery. Factors influencing choice of place of delivery are agegroup, social category, education and religion of the respondents. In the study area, trend of delivery at health institution is remarkably increased since last decades but there is found strong differentials in low socioeconomic status of women. Ignorance and dominance of mother-in-law plays a major role in family matters. Considering the institutional delivery as the primary strategy for promoting safe motherhood, it is necessary that all women should be encouraged to avail institutional delivery care. The Government health agencies need to strengthen regulation of delivery care, especially, monitor prenatal outcomes. Family preference for hastening delivery and early discharge also require educational efforts. In order to make better maternal and child health, the health worker needs to provide knowledge to women on behaviour and communication change and proper maternal health information are the best options to reduce the practice of home delivery among rural women. Study recommends that government should take concrete steps to change the mind-set of the people and encourage them to deliver at institution through targeted programmes.

\section{REFERENCES}

[1] Dadhich J, Paul V: (2004): State of India's newborns. New Delhi: National Neonatology Forum and Washington DC: Save the Children.

[2] Vora CS, Mavalankar1 DV, Ramani KV, Upadhyaya M, Sharma B, Iyengar S, (2009): Maternal Health Situation in India: A Case Study, Journal of Health Population Nutrition, Vol. 27(2), Pp. 184-200.

[3] United Nation: The millennium development goal report, (2010): Improve maternal health. http://www.mdgs.un.org/unsd/mds/resource/static /products/progress

[4] WHO, UNICEF, UNFPA and World Bank, (2015): Trends in Maternal Mortality, 1990-2008. Zeneva: World Health Organization.

[5] WHO: World Health Statistics, (2013): Switzerland: World Health organization, WHO Press, 20 Avenue Appia, 1211 Geneva.

[6] World Health Organization, (2015): Millennium development goals: progress towards the health- related millennium development goals; improved maternal health (MDG 5), fact sheet. N 290: available at http:// www.who.int/ mediacenter/ factsheet/ fs290/ en/

[7] National Family Health Survey-III, (2005-06): Ministry of Health and Family Welfare, Government of India.

[8] District Level household and Facility Survey-III, (2007-08): International Institute for Population Studies (IIPS), Mumbai, India.

[9] Census, (2011): Government of India (Office of the Registrar General and Census Commissioner).

[10] Ministry of Health and Family Welfare (MoHFW), (1997): Reproductive and Child Health Programme: Schemes for Implementation, Department of Family Welfare, New Delhi.

[11] Mpembeni, R.N.M., J.Z. Killewo, M.T. Leshabari, S.N. Massawe, A. Jahn and D. Mushi, (2007): Use pattern of maternal health services and determinants of skilled care during delivery in Southern Tanzania: implications for achievement of MDG-5 targets, BMC Pregnancy Childbirth, 7: 29.

[12] Chakraborty, N., M.A. Islam, R.I. Chowdhury, W. Bari and H.H. Akhter, (2003): Determinants of the use of maternal health services in rural Bangladesh. Journal of Health Promotion, Vol.18, Pp. 327-337.

[13] Stephenson, R., A. Baschieri, S. Clements, M. Hennink. and N. Madise, (2006): Contextual influences on the use of health facilities for childbirth in Africa. American Journal of Public Health, Vol. 96, Pp.84-93.

[14] Navaneetham, K. and A. Dharmalingamb, (2002): Utilization of maternal health care services in Southern India, Social Science Medicine, Vol. 55, Pp. 1849-1869.

[15] Mayhew, M., P.M. Hansen, D.H. Peters, A. Edward, L.P. Singh and V. Dwivedi, (2008): Determinants of skilled birth attendance in Afghanistan: a Cross- sectional study, American Journal of Public Health, Vol. 98, Pp. 1849-1856.

[16] Houweling, T.A.J., C. Ronsmans, O.M.R. Campbell. and A.E. Kunst, (2007): Huge poor-rich inequalities in maternity care: an international comparative study of maternity and child care in developing countries, Bulletin World Health Organization, 85: 745-754. 
[17] Shahla Ramzan, M., Inayat Khan, Faisal Maqbool Zahid, Sajid Rasul and Shamim Rafiq, (2013): Socioeconomic differences among distirct of the Punjab: A cluster analysis approach based on Multiple indicator cluster survey, World Applied Science Journal, Vol. 21(2), Pp. 293-300.

[18] Letamo, G. and S.D. Rakgoasi, (2003): Factors associated with the non-use of maternal health services in Botswana, Journal of Health Population and Nutrition, Vol. 21, Pp. 40-47.

[19] Celik, Y. and D.R. Hotchkiss, (2000): The socio-economic determinants of maternal health care utilization in Turkey, Social Science Medicine, Vol. 50, Pp. 1797-1806.

[20] Mekonnen, Y. and A. Mekonnen, (2003): Factors influencing the use of maternal healthcare services in Ethiopia, Journal of Health Population Nutrition, Vol. 21, Pp. 374-382.

[21] http://www.dghs.gov.bd/index.php/en/mis-docs/epi/121-bengali/menu-articles/1117-ces-coverageevaluation-survey-report. 